\title{
BMJ Open Athena SWAN and gender diversity: a UK-based retrospective cohort study
}

\author{
Yunyu Xiao (D) , ${ }^{1}$ Edward Pinkney, ${ }^{2}$ Terry Kit Fong Au, ${ }^{3,4}$ Paul Siu Fai Yip ${ }^{2,5}$
}

To cite: Xiao Y, Pinkney E, Au TKF, et al. Athena SWAN and gender diversity: a UK-based retrospective cohort study. BMJ Open 2020;10:e032915. doi:10.1136/ bmjopen-2019-032915

- Prepublication history and additional material for this paper are available online. To view these files, please visit the journal online (http://dx.doi. org/10.1136/bmjopen-2019032915).

Received 11 July 2019 Revised 11 December 2019 Accepted 13 January 2020

Check for updates

(c) Author(s) (or their employer(s)) 2020. Re-use permitted under CC BY-NC. No commercial re-use. See rights and permissions. Published by BMJ.

${ }^{1}$ Silver School of Social Work, New York University, New York, New York, USA

${ }^{2}$ Centre for Suicide Research and Prevention, University of Hong Kong, Pokfulam, Hong Kong

${ }^{3}$ Department of Psychology, University of Hong Kong,

Pokfulam, Hong Kong

${ }^{4}$ President's Office, University of Hong Kong, Pokfulam, Hong Kong

${ }^{5}$ Department of Social Work and Social Administration, University of Hong Kong, Pokfulam, Hong Kong

Correspondence to

Dr Paul Siu Fai Yip;

sfpyip@hku.hk

\begin{abstract}
Objectives To promote gender diversity and equity in higher education, Athena Scientific Women's Academic Network (SWAN) supports and recognises higher education institutions (HEI) in advancing the careers of women through charter commitment, awards, training and advocacy since 2005. Most evaluation studies, however, are based on qualitative assessments. This study sought to (1) examine the relationship between Athena SWAN accreditation/awards in the UK and gender diversity of leaders and senior academics using quantitative data from 2012/2013 to 2016/2017, and (2) explore the associations between Athena SWAN awards and university performance as measured by overall scores in global ranking systems. Design Retrospective cohort study based on the UK HEls. Setting Higher education sector in the UK provided by the Higher Education Statistics Agency.
\end{abstract}

Participants 148 HEls who provided employment data on female-to-male ratios ( $55 \%$ complete data) for each academic year between 2012/2013 and 2016/2017.

Primary and secondary outcome measures Gender diversity, defined as female representation rates of positions in managerial leadership (eg, heads of institutions, department heads) and professors. The Quacquarelli Symonds (QS) World University Rankings scores, an indicator of research, teaching, employability and internationalisation, were collected to measure university performance.

Results Gender diversity of managerial leaders and non-managerial professors at all levels of Athena SWAN status has improved over the 5 years. Linear mixed effects models identified that Athena SWAN awardees had lower female representation than non-awardees in managerial leadership positions $(p<0.05)$, while the gap was narrowed among Silver awardees over time. Athena SWAN Charter members had increasingly higher female representation than those not in the Charter $(p<0.05)$. Silver-award institutions ranked higher in QS rankings than Bronzeaward institutions $(\beta=11.80, p<0.05)$.

Conclusions There are overall rising trends in gender diversity from 2012/2013 to 2016/2017. Athena SWAN members showed greater and faster growth in female representations. Silver awardees had greater university performance than Bronze awardees.

\section{INTRODUCTION}

Gender inequality has been persistent in academic medicine. ${ }^{1-6}$ Athena Scientific Women's Academic Network (SWAN) gender equality scheme, which was launched in 2005 by the Equality Challenge Unit (ECU) in the
Strengths and limitations of this study

- This is the first quantitative study to retrospectively examine gender diversity in leadership and academic positions across higher education institutions (HEI) with different Athena Scientific Women's Academic Network (SWAN) status in a longitudinal design using 5-year data collected from the Higher Education Statistics Agency.

- We showed that gender diversity of managerial leaders and non-managerial professors across all HEls increased over the 5 years (2012/2013-2016/2017).

- Levels of Athena SWAN accreditations/awards were positively associated with the increasing rate of change in female representation, while the extents of relationship differ across groups.

- Silver awardees had better university performance measured by Quacquarelli Symonds world ranking overall scores than Bronze awardees over time.

- Limitations include lack of controlled variables and data longer than 5 years.

UK and currently managed by Advance HE, aims to support a more supportive, inclusive and flexible working environment, with less discrimination. ${ }^{7}$ Athena SWAN has become an influential global movement, with expansion to Ireland and Australia since 2015, ${ }^{8}$ and recent adaptations of similar models in the USA and Canada. Despite increasing policies designed to reduce gender imbalance, under-representation of women in higher education institutions (HEI) continues to exist, particularly among senior levels of managerial leaders and professors. ${ }^{3} 910$ In the UK, only $21 \%$ of clinical academics were women, and such gender inequality increases with seniority, with only $8.4 \%$ of all staff being female professors in 2017. ${ }^{9}$ Similarly, among key managerial leadership roles across 173 HEIs in the UK, $27 \%$ of governing bodies are chaired by a woman, and only $29 \%$ have a woman vice-chancellor or principal. ${ }^{5}$ This study focuses on HEIs in the UK due to it being the original country of Athena SWAN and providing a useful sample size of HEIs for evaluating the impact of Athena SWAN. 
Gender equality has an important impact on higher education and research. Under-representation of women in HEIs is associated with individual and institutional costs across different levels. First, among faculty members, women were found to be more likely than men to perceive discrimination in promotion, resource, salary, fellowship and scientific awards, creating obstacles to satisfaction and retention of the women in HEIs. ${ }^{11}$ Experiences of gender bias and discrimination could be a threat to women's physical and mental health, ${ }^{12}$ and may even bring intergenerational effects on child health. ${ }^{13}$ Second, women are under-represented as research participants in university communities. Lack of female research participants and ignorance of gender differences can result in inaccurate research conclusions. ${ }^{14}$ Since women may respond differently to diseases, gender bias could ultimately affect the effectiveness of medical treatment choices. ${ }^{15}$ Third, losing qualified women in the pipeline for leaders in clinical practice and academic research, while having more than half female medical students entering the medical schools, ${ }^{16}$ is considered a waste of public investment in human capital. ${ }^{17}$ Finally, the shortage of female researchers participating in the research agenda of clinical medicine may bring implicit bias to the fields of clinical medicine and public health. ${ }^{9} 18$ Accordingly, researchers have recently suggested including gender balance in assessing research impact of HEIs. ${ }^{14}$

HEIs have a broad set of responsibilities to society, as educators, as research bodies, as employers and as civic institutions. ${ }^{19}$ The impact of HEIs can be measured using academic metrics (eg, graduate achievements, research influence), as well as broader socially oriented measures that indicate a commitment to social values (eg, societal well-being, diversity and equal opportunity). These broader measures of social value can be challenging to quantify and are typically not recognised in rankings of institutions. ${ }^{20}$ As a result, there is a need for independent frameworks and recognition to support and incentivise institutions to prioritise social responsibilities.

To address unequal representation of women and its adverse effects in academic sciences, as well as advancing the career opportunities for women in higher education and research, ${ }^{21}$ the Athena SWAN Charter was established in 2005. Managed by the ECU since its launch, Athena SWAN offers HEIs who join the Charter the opportunity to demonstrate excellence in supporting gender diversity practices by progressing through Bronze, Silver and Gold awards. Both Bronze and Silver awards involve collection and submission of data, while Bronze awards recognise detailed plans for making improvements and Silver awards recognise retrospective achievements and milestones. As of March 2019, no educational institutions had attained Gold awards.

In 2011, the National Institute for Health Research (NIHR) announced that from 2016 onwards, only institutions in receipt of an Athena SWAN Silver award would be shortlisted for research funding awards. In 2012, these funding awards were worth upwards of $£ 100000$ to some institutions, creating a substantial incentive for institutions with medical schools to pursue Athena SWAN awards. ${ }^{22}$ Initially focused on careers of women in Science, Technology, Engineering, Mathematics and Medicine (STEMM), the scope of Athena SWAN expanded in 2015 to cover other disciplines, non-academic staff, trans-sexual staff and students. Recently, researchers demonstrated that Athena SWAN can be usefully framed as complex social interventions embedded in a complex system. ${ }^{23}$ Acknowledging, planning and evaluating Athena SWAN's contextually embedded systematic approach is imperative to initiate effective gender equality structural and cultural changes.

Several studies have attempted to evaluate the influences of Athena SWAN, and results have been mixed. Some studies identified positive effects. ${ }^{346}$ For instance, a report commissioned by ECU found that $90 \%$ of institutional champions (facilitators appointed within institutions) and $81 \%$ of departmental champions agreed that Athena SWAN had a positive impact on gender equity. ${ }^{24}$ A recent mixed-methods study indicated that widespread development and implementation of Athena SWAN plans linked to the NIHR funding incentives in medical science could benefit the perception of cultural inclusiveness among women in the HEIs. ${ }^{25}$ Over half of Athena SWAN Champions demonstrated progress in promoting female career opportunities. Academic staff in HEIs with Silver award were more satisfied with their "career performance/development review with opportunities for training and development' than staffs in departments without the award. Munir and colleagues also found evidence of improvements in institutional engagement and communication around diversity practices after receiving an Athena award..$^{24}$ Members of participating institutions reported 'visible representation of more women in key positions and senior roles'. On reasons for applying for an Athena SWAN award, the majority of HEIs reported they thought it was the 'right thing to do' and that they were committed to gender equality.

Other studies revealed unintended and sometimes adverse consequences, which perhaps highlight the complexity and challenges of implementing the Athena SWAN recommendations. First, the tendency for women to be appointed by institutions as Athena SWAN leads, and the large time commitment and labour-intensive activities associated with meeting award criteria, may paradoxically hamper the research trajectory of those women involved. ${ }^{2}$ Concerns have been raised about adding administrative burden to institutions during the application process. ${ }^{26}$ Second, the connection between the award and NIHR funding could pervert incentives and lead to overemphasis on meeting specific award criteria (ie, box ticking) at the expense of fundamental and systematic advancements in gender diversity and support. ${ }^{2}$ Third, overlooking the patterns of intersectionality (ie, the intersection of gender with ethnicity) may result in insufficient 
consideration of the unique disadvantages experienced by certain subgroups. ${ }^{26}$ In fact, recent studies suggested that while gender equity programmes have the potential to support women's career development and address gender inequity, they can also reinforce particular inequities. $^{3}{ }^{27}$ It is crucial to address fundamental gender equality issues, enhance family-friendly policies and reinforce cultural changes through high-level institutional support, along with national policies and addressing of societal norms. ${ }^{28}$ The partially inconsistent evaluation results call for further studies to evaluate the effectiveness of Athena SWAN awards.

Existing studies almost exclusively used a qualitative design. The only quantitative study of Athena SWAN used employment data from university medical schools between 2004 and $2013 .^{22}$ That study found that institutions affected most by the NIHR announcement appeared to be more motivated to attain Athena SWAN awards, but there were no significant differences in the rates of female employment (including lecturers, senior lecturers and professors) over time between those institutions that signed up for the Athena SWAN Charter and those that did not. ${ }^{22}$ A key limitation of the study was that its data sampling period ended 3 years before the 2016 NIHR deadline that required funding applicants to have a Silver award. In other words, the effects of any institutions that subsequently met the deadline were excluded. To date, the relationship between Athena SWAN awards and female employment has also remained unclear.

The present study attempted to address the major gaps in existing knowledge and to explore the relationship between Athena SWAN affiliation levels and gender diversity in managerial leadership roles and senior academics. Specifically, this study examined the effects of levels of Athena SWAN award and the changes of female representation in (1) managerial leadership positions, and (2) professors focusing on academic duties. Moreover, to understand the effects of Athena SWAN recipients on the university performance, this study examined (3) whether Athena SWAN award levels are associated with the Quacquarelli Symonds (QS) World University Rankings.

Diversity in senior managerial and academic positions, as an indicator of the progress of women achieved through their career paths, is a key measure within the higher education equity and diversity agenda, and hence an essential indicator of the success of Athena SWAN. Importantly, the 5-year study period included the roll-out of the NIHR funding requirement in 2016. Based on the criteria for receiving Athena SWAN award and a recent evaluation report, ${ }^{29}$ we hypothesised that Athena SWAN awardees would show increasing changes of female representation in managerial leaders and non-managerial professors. In addition, we hypothesised that recipients of a Silver award would have better overall scores of QS ranking than those receiving a Bronze award.

\section{METHODS}

\section{Data and measures}

Gender diversity

HEI employment data were provided by the Higher Education Statistics Agency (HESA), categorised by gender, for each academic year from 2012/2013 to 2016/2017. Female-to-male ratios were rounded to the nearest five persons to comply with data protection laws. Female representation rates of managerial leadership and professor groups were calculated separately. This study focuses on HEIs in the UK since Athena SWAN was originally implemented in the $\mathrm{UK}$, and we were able to collect enough employment data from HEIs to conduct longitudinal evaluation across 5 years. For ease of exposition, 'Leaders' refers to managerial leaders including heads of institutions, academic areas, centres and key administrative functions; this category included professors with major managerial leadership such as heading departments (HESA contract levels A-E2). 'Professors' refers to full professors without these line management responsibilities (HESA contract level F1).

HESA contract levels were as follows: ${ }^{30}$

A: Head of institution-vice-chancellor/principal/ equivalent

B: Deputy vice-chancellor/pro-vice-chancellor/chief operating officer/registrar/secretary

C1: Head/director of major academic area

C2: Director of major function/group of functions, for example, finance, corporate services, human resources

D (1-3): Head of a distinct area of academic responsibility centre, for example, head of school/division/ department

E1: Head of a subset of an academic area/director of a small centre (may include professors who head departments/research centre)

E2: Senior function head

F1:Professor (without line managementresponsibilities) Examining both managerial leaders (A-E) and professors without line management responsibilities (F1) allowed for exploring managerial leadership versus academic career pathways independently. Since many higher education leaders have progressed from their roles as professors, any contrast in findings between the groups may also reflect different stages of careers in HEIs.

\section{Athena SWAN awards}

Information about Athena SWAN award recipients, Charter members and action plans is published and maintained on the ECU and institutional websites. ${ }^{31}$ To ensure accuracy, two authors (YX, EP) individually collected and validated the award history during the study period (2012/2013-2016/2017). Athena SWAN is based on 10 key principles and contains three levels of awards (Bronze, Silver and Gold). ${ }^{32}$ Bronze institution awards require an assessment of gender equality (quantitative and qualitative), a 4-year action plan based on the assessment and an organisational structure (eg, self-assessment team) to implement the proposed actions. Silver awards recognise 
institutions that have successfully implemented the previously proposed actions since receiving a Bronze award and demonstrated the impact of Athena SWAN activities. Both the institutions and departments within the institutions can apply, while departmental awards require evidence of identifying challenges and planning actions in addition to the institutional levels. ${ }^{132}$ Since this study focused on gender diversity in HEIs, only institutional-level awards were examined. No institutions had Gold-level awards to date, hence for this study, there were three levels (Nonrecipient Charter institutions who had committed to the Charter but had not received an award $={ }^{\prime} 0$ ', Bronze $={ }^{\prime} 1$ ', Silver='2') of Athena SWAN accreditation for Athena Charter members and four levels (Non-Athena $={ }^{\prime} 0$ ', Nonrecipients='1', Bronze='2', Silver='3') for all HEIs.

This study included 148 HEIs. By the last year of the study period (2016/2017), the sample consisted of 111 Athena SWAN members, among which 79 (53.4\%) were Bronze institutions, $14(9.5 \%)$ were Silver institutions and $16(12.2 \%)$ were non-recipient Charter institutions. The rest of HEIs $(n=37)$ were non-Athena institutions.

\section{Duration of award}

Since institutional efforts to achieving gender equity might show effects on female representation cumulatively since their participation in the Athena SWAN programme, this study also took the duration of award (ranges from 0 to 5), measured as the length of year from the first award until the last year of study period (2016/2017), into account.

\section{University performance}

The QS World University Rankings overall scores (ranging from 0 to 100) were employed to assess the university performance. Compared with the other world ranking systems, among which the Academic Ranking of World Universities list predominantly focuses on faculty accomplishments and research output, ${ }^{33}$ the ranking of the Centre for Science and Technology Studies is mainly based on bibliometric data, ${ }^{34}$ and the Times Higher Education World University Rankings focuses on institution's performance across 13 indicators, including teaching, research, knowledge transfer and international outlook, ${ }^{35}$ the QS World University Rankings measures six simple metrics across academic reputation, employer reputation, faculty/ student ratio, citations per faculty, international faculty ratio and international student ratio. ${ }^{36}$ While imperfect, QS rankings reflect the global reputation of institutions, ${ }^{37}$ provided a more holistic assessment of university performance rather than focusing on bibliometric indicators and have been shown to be consistent and valid across years. Hence, the QS overall scores (indicators for QS ranking) were used to measure university performance.

\section{Statistical analysis}

First, descriptive statistics were used to report the trends in female representation in Leaders and Professors groups among all HEIs and across Athena SWAN levels of accreditation/award from 2012/2013 to 2016/2017 (table 1, figures 1 and 2). Rate growth was calculated by: (1) calculating the relative female representation among Leaders/Professors of specific Athena SWAN award in a specific year $(i) ;(2)$ determining the relative increase or decrease in the female representation among Leaders/ Professors of specific Athena SWAN award between 2 years (this can be computed by expressing how much (as a percentage) the female representation has increased or decreased compared with its value in the year before $[i$ $-1]$ ); and (3) adding the relative increased or decreased values to determine the overall growth of the underlying rates of change during the 5-year data collection period. The following equation was used:

$$
\text { Rate growth }=\sum_{i=1}^{n-1} \frac{r_{i+1}-r_{i}}{r_{i}}
$$

where $r_{i}=\frac{n_{i}}{N_{i}}, n_{i}$ is the percentage of female representation for the $i^{t h}$ year and $N_{i}$ is the highest possible frequency value for the specific Athena SWAN award in that year (ie, total number of institutions received the specific Athena SWAN award). The same method was applied to describe the trend of change rate for QS overall score among all HEIs and across Athena SWAN award levels (ie, Bronze and Sliver) of accreditation/award from 2012/2013 to 2016/2017 (table 1).

Second, $t$-test was used to compare the overall scores of QS rankings in each study year between Silver and Bronze awardees (table 1). Cohen's $d$ was used to measure the effect size.

Third, linear mixed effects models were employed to examine the effect of Athena SWAN accreditation/award levels (ie, non-Athena members, non-recipients, Bronze and Silver awards) on female representations in Leaders and Professors among Athena Charter members and all HEIs after adjusting for time effect ('year'). As institutions may differ in their duration of receiving and developing action plans for gender equality, duration of award was adjusted statistically (table 2). To examine whether the effects of Athena SWAN award levels on female representation would be different with time increased, two-way interaction terms between Athena SWAN award levels and year were added to the mixed effects models. Independent variable 'year' was centralised before the creation of interaction term to reduce multicollinearity (table 3). The same method was applied to examine the effect of Athena SWAN award levels (Bronze or Silver) on QS overall scores (table 4). To examine possible nonlinear effects of time, we conducted additional analyses treating 'year' as discrete variables and using the baseline $(2012 / 2013)$ as the reference year. Results were shown in the online supplementary appendix. Goodness of fit for each model was estimated based on Akaike information criteria and Bayesian information criteria. ${ }^{38}$ Smaller values of each of these statistics indicate better model fit. Statistical manipulations were undertaken using STATA software V.14.0 (StataCorp, College Station, Texas, USA) and SAS software V.9.4 (SAS Institute). 
No patients or members of the public were involved in this study.

\section{RESULTS \\ Descriptive statistics}

Table 1 presents the distributions of female managerial leaders and non-managerial professors in HEIs, as well as QS overall scores from 2012/2013 to 2016/2017. On average, there were higher percentages of female leaders than professors across the 5 years. Female representation in leaders was consistently the highest among non-recipients and the lowest among Silver awardees. For female professors, non-Athena institutions had the highest percentage, whereas Silver awardees showed the lowest.

The average QS overall scores increased across years from 2012/2013 (mean=57.75 [SD=20.88]) to 2015/2016 (mean=63.15 SD=18.73]), but decreased in 2016/2017 (mean=56.93 [SD=19.95]). Institutions with Silver awards had significantly higher QS overall scores than those with Bronze awards $(p<0.05)$ in each year across the study period.

\section{Changes of female representation over time}

As shown in figure 1 , over the 5 years, non-recipient Charter institutions had higher percentages of female leaders than non-Athena institutions. Surprisingly, nonrecipient Charter institutions also had higher percentages of female managerial leaders than both Bronze and Silver institutions.

Over the five academic years examined, gender diversity in leadership positions has improved across all HEIs. As shown in table 1, the rates of female increased by $8.4 \%$ among managerial leaders and $7.6 \%$ among professors without line management duties, while different growth rates were observed for different Athena SWAN levels of accreditation/award. Silver institutions were moving towards gender equity at a faster rate $(20.3 \%)$ than nonrecipient Charter institutions (11.1\%), Bronze institutions $(9.0 \%)$ and non-Athena institutions $(2.4 \%)$. The gaps in gender diversity between the groups have also narrowed proportionately, suggesting that Athena SWAN levels of accreditation/award may be associated with better overall progress in moving towards gender equity in managerial leadership.

As seen in figure 2, non-Athena institutions had higher percentages of female non-managerial professors than Athena institutions, regardless of their Athena SWAN levels of accreditation/award. For professors, non-recipient Charter institutions had the highest rate of increasing gender diversity $(17.5 \%)$ over institutions from other levels, which was followed by the growth rate of Silver awardees (14.3\%) and Bronze awardees (5.7\%). Non-Athena institutions had the lowest rate of change $(1.1 \%$, see table 1$)$. 


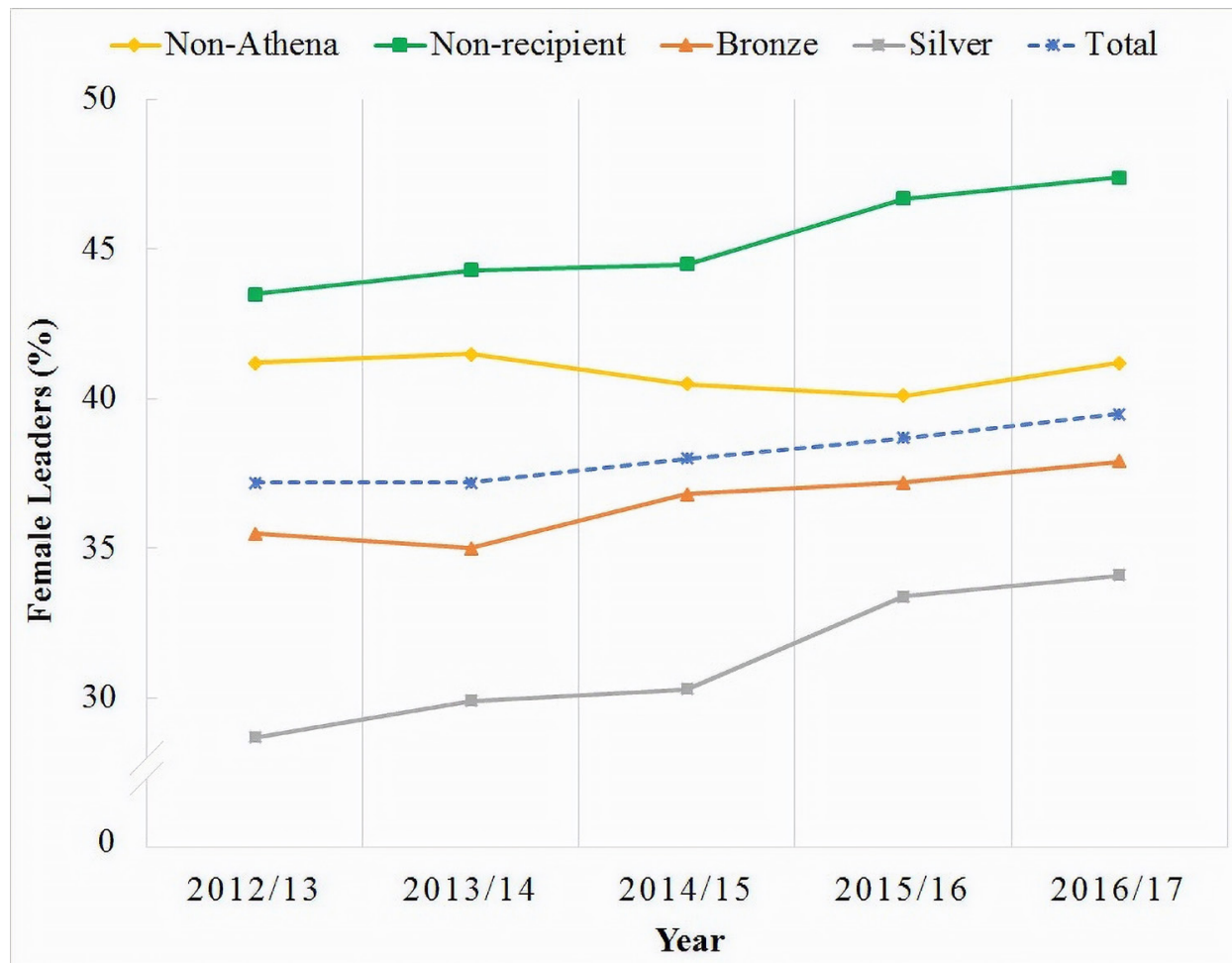

Figure 1 Changes of female representation in leaders by Athena Scientific Women's Academic Network (SWAN) levels from $2012 / 2013$ to $2016 / 2017$.

\section{Athena award level and gender diversity}

Table 2 reports the results of linear mixed effects model of gender diversity in managerial leaders and nonmanagerial professors. There were positive effects of year on female representation in both managerial leaders and non-managerial professors across all Athena SWAN accreditation/awards (table 2). With time increased, the female representation increased in both managerial leaders

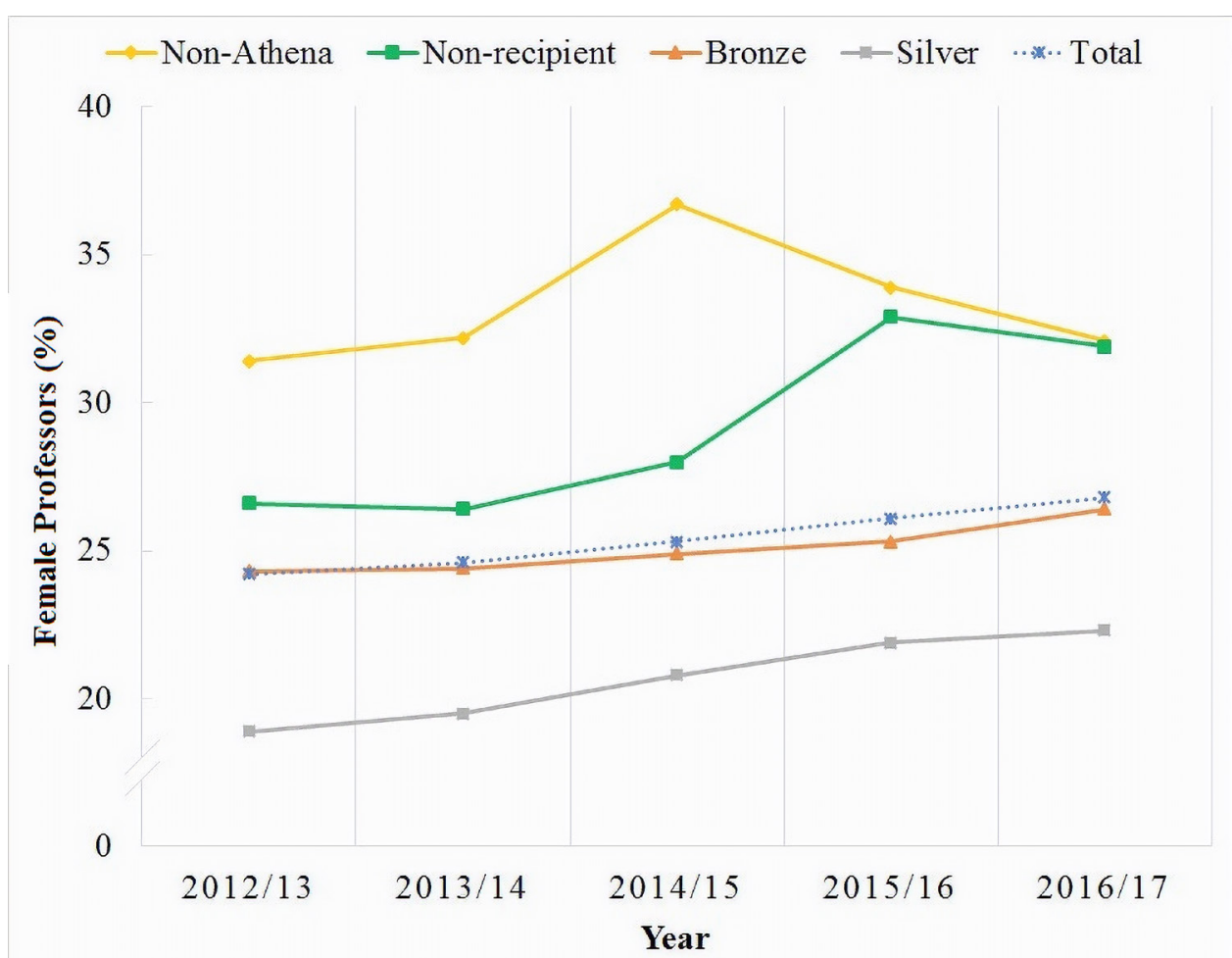

Figure 2 Changes of female representation in professors by Athena Scientific Women's Academic Network (SWAN) levels from $2012 / 2013$ to $2016 / 2017$. 


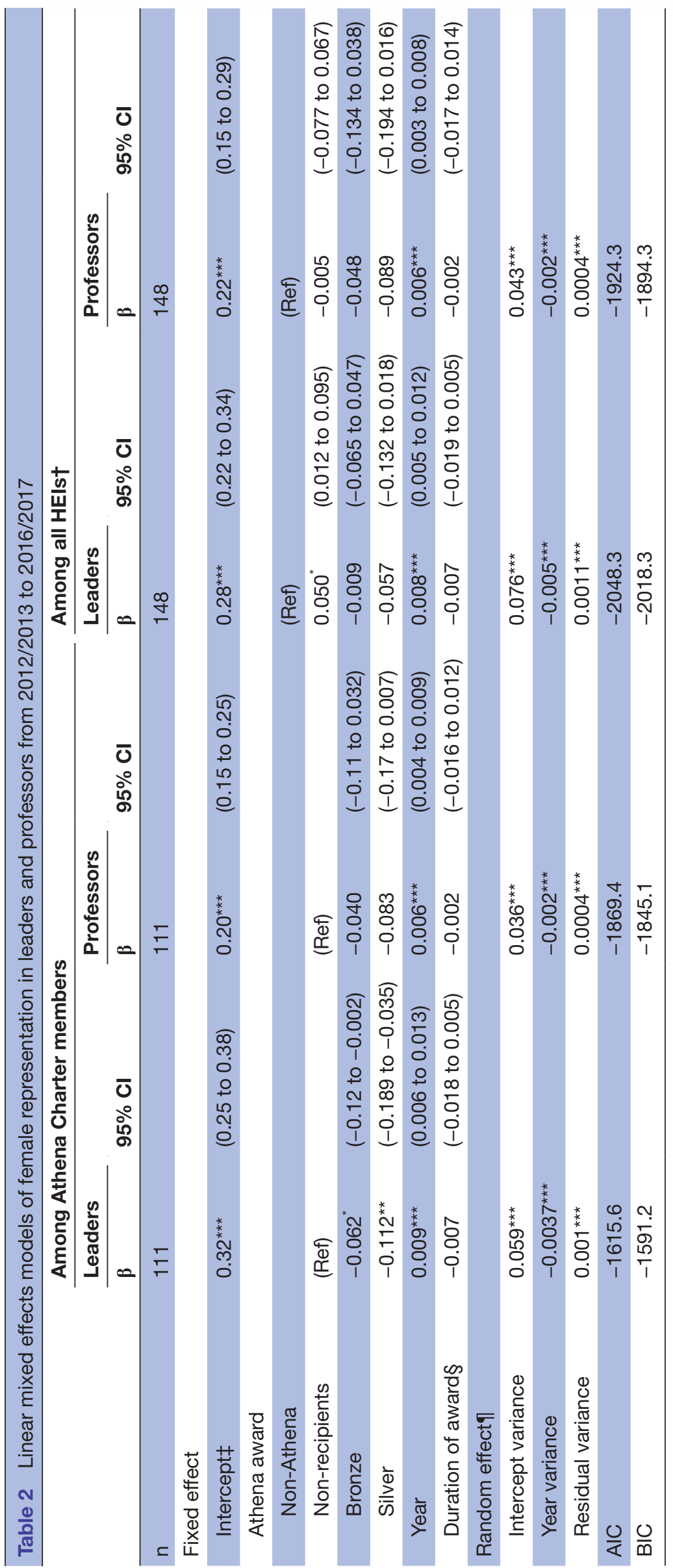

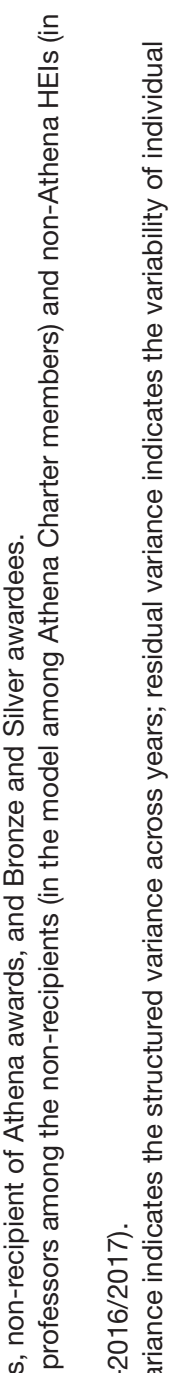

$\stackrel{\text { m }}{s}$

응

$\stackrel{\overrightarrow{\bar{g}}}{\overrightarrow{9}}$

흠

ह

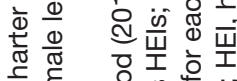

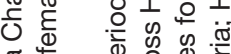

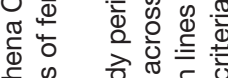

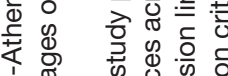

落

ब

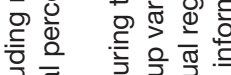

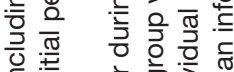

농

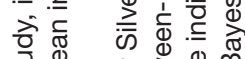

एँ

造

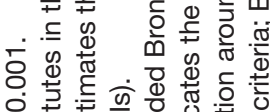

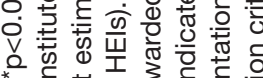

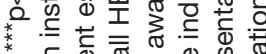

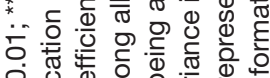

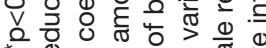
*

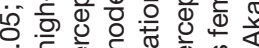

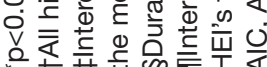



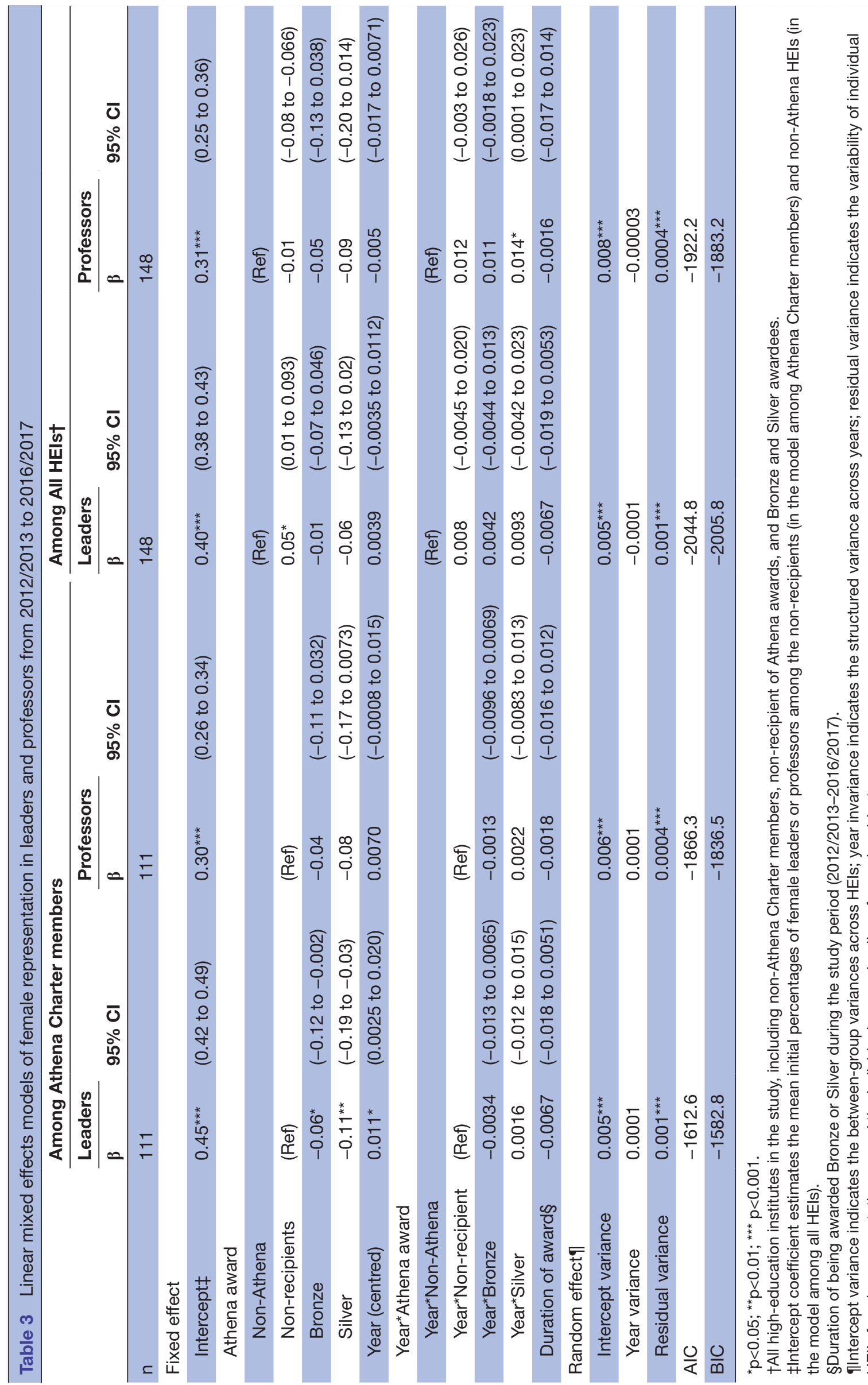

紧

के

옹

ర్ల్ర

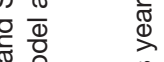

类

일

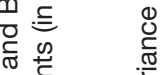

$\vec{N}$

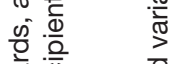

要

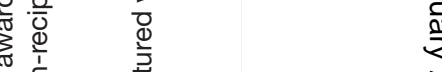

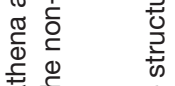

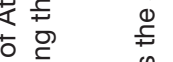

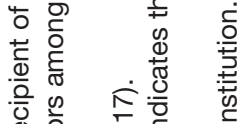

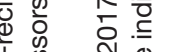

范

劉文 के

ह क क

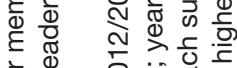

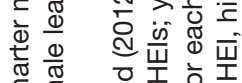

ठั

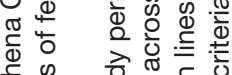

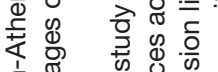

员

늏

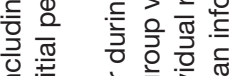

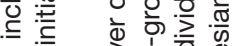

충 के

के

ه

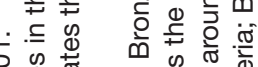

N

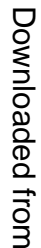

룽

응 
Table 4 Linear mixed effects models of QS scores in leaders and professors from 2012/2013 to 2016/2017

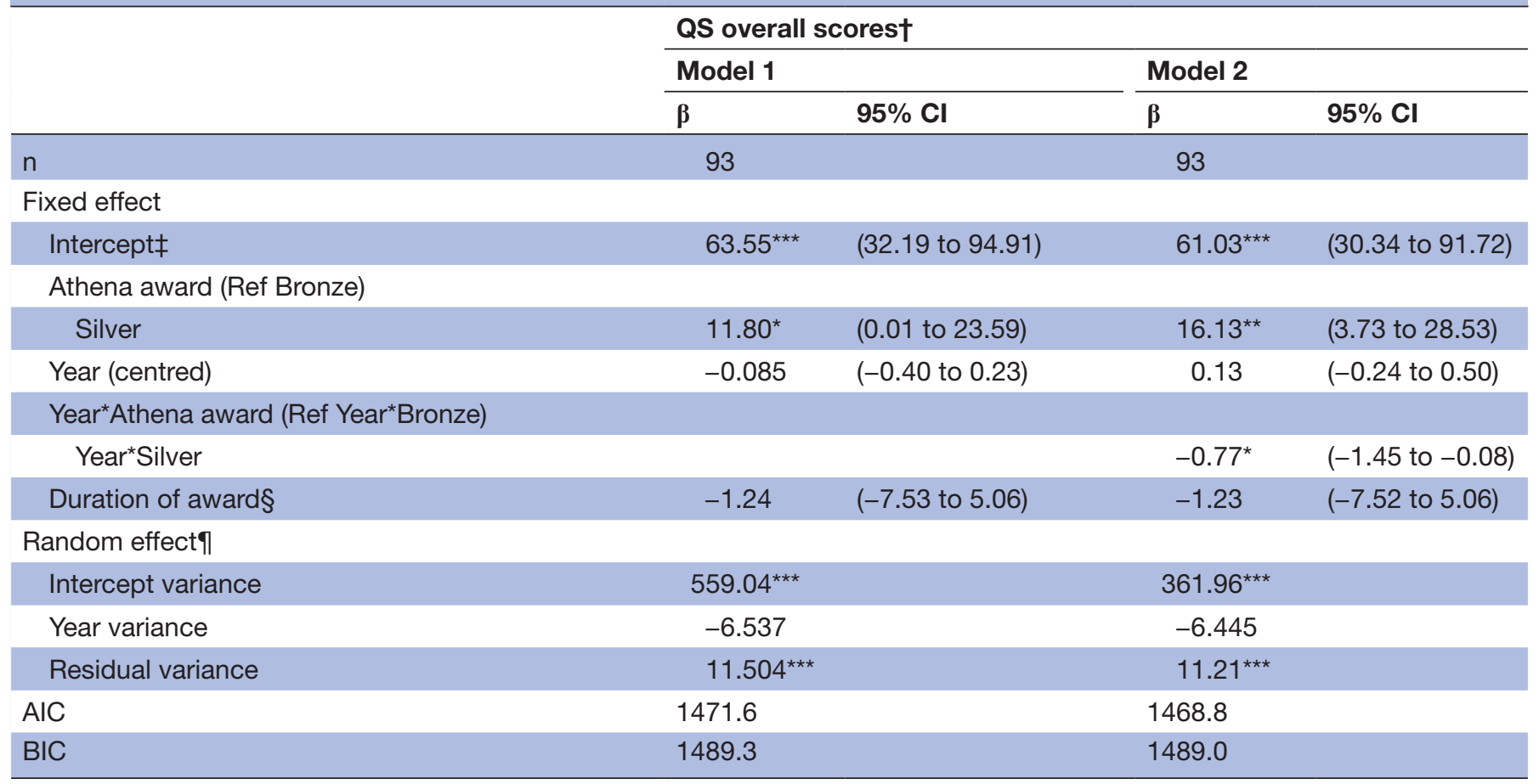

${ }^{*} \mathrm{p}<0.05 ;{ }^{* *} \mathrm{p}<0.01 ;{ }^{* * *} \mathrm{p}<0.001$.

†Only conducted among Bronze and Silver awardees.

łIntercept coefficient estimates of the mean initial QS score among Bronze awardees.

§Duration of being awarded Bronze or Silver during the study period (2012/2013-2016/2017).

IIntercept variance indicates the between-group variances across higher education institutions (HEI); year invariance indicates the structured variance across years; residual variance indicates the variability of individual HEl's female representation around the individual regression lines for each subject.

AIC, Akaike information criteria; BIC, Bayesian information criteria; QS, Quacquarelli Symonds.

and non-managerial professors, even without considering the effect of Athena SWAN. Among Athena SWAN charter members, differences across Athena SWAN award levels were observed only in managerial leadership positions, but not among non-managerial professors. Being Bronze $(\beta=-0.062, p<0.05)$ and Silver $(\beta=-0.112, p<0.01)$ awardees was associated with decreases in female leaders, compared with non-recipient Charter institutions.

Among all institutions, Athena SWAN Charter members, though not receiving awards during the study period, had significantly greater percentages of female leaders $(\beta=0.050, p<0.05)$ than non-Athena institutions. Athena SWAN levels of accreditation/award were not associated with differences in female representation among nonmanagerial professors. When considering the non-linear effects, results showed that compared with the 2012/2013 baseline, percentages of women in both managerial leaders and non-managerial professors have increased since 2014/2015 (online supplementary appendix 1).

Adding the interactions between year and the Athena SWAN levels of accreditation/award revealed significant interaction effects on female representation in professor positions (table 3). Among all HEIs, while being a Silver awardee had lower percentage of female managerial leaders than non-Athena institutions in the beginning, that gap was narrowed with the increase in years $(\beta=0.0014$, $\mathrm{p}<0.05)$. Results of the non-linear effects models revealed that the buffering effects of time started at 2015/2016 (see online supplementary appendix 2). While Silver awardees showed lower rates of female professors than non-Athena institutions $(\beta=-0.114, \mathrm{p}<0.05)$, these patterns have been slower significantly from $2015 / 2016$ to $2016 / 2017$ $(\beta=0.058, p<0.01)$.

\section{Athena award level and university performance}

Table 4 indicated that Silver awardees, relative to Bronze award recipients, had greater QS overall scores $(\beta=11.8$, $\mathrm{p}<0.05)$. In addition, the significant interaction between year and Athena SWAN accreditation/award suggested, compared with universities of Bronze awardees, with time increased, the QS overall scores among HEIs with Silver awards have increased in lower rates $(\beta=-0.77, \mathrm{p}<0.05)$. Considering the non-linear effects (online supplementary appendix 3), results showed substantial decrease in QS overall scores in 2015/2016 and 2016/2017, compared with 2012/2013. There was only one non-recipient Charter institution covered in QS rankings across the study period (ie, London School of Economics and Political Science, top 37 institution globally), suggesting that most of the institutions in the UK considered to be globally elite have applied for and received Athena SWAN 
awards, with the highest ranked institutions mostly having attained Silver awards.

\section{DISCUSSION}

A central goal of Athena SWAN is to move HEIs and the sector towards gender equity. The rising trends in gender diversity found in this study are generally encouraging. In all levels of Athena SWAN affiliation, and even in those without affiliation, gender diversity of managerial leaders and non-managerial professors has increased over the 5 years examined here $(2012 / 2013-2016 / 2017)$. In particular, we identified a faster rate of increase among managerial leaders, schools with Silver award and nonrecipient institutions compared with those not affiliated with Athena SWAN. During the same period of time, the average QS overall scores have increased from 2012/2013 to $2015 / 2016$ but later decreased among both Bronze and Silver awardees. Institutions with Silver awards also had better university performance than those with Bronze awards. This is the first study that quantitatively examined the association between different levels of Athena SWAN awards/accreditation, gender diversity and university performance.

For female managerial leaders, non-recipients showed greater female representation than Athena SWAN award recipients and non-Athena SWAN institutions. An examination of the 18 non-recipient institutions included in the current study showed that they joined the Athena SWAN Charter later than $2015 / 2016,{ }^{39}$ which left them a shorter time to meet the award criteria, even though they have high level of female representation initially. Athena SWAN awardees, importantly, showed higher growth rate of female managerial leader representation than non-Athena institutions. Such increasing rates even became faster among Athena institutions, suggesting the positive effect of involving in the Athena SWAN agenda on promoting gender equity. Notably, Silver awardees pushed past the point of one-third of managerial leaders being female, a figure previously suggested to be an essential milestone-namely $30 \%$-for leadership board diversity affecting organisational performance. ${ }^{40}$

For non-managerial professors, the findings are mixed. Regardless of Athena SWAN accreditations/award levels, less than one-third of such professors were women at the end of the 5-year period examined in this study (ie, 2012/2013-2016/2017). Although all four groups moved towards greater gender diversity, the rates of growth were lower than those among female leaders, which is striking, given that around half of postgraduate research students are female. ${ }^{41}$ The slow increase can be partly explained by the fact that while Athena SWAN awards may have impact on the recruitment of junior female faculty members, it may be difficult or take a longer period of time for junior faculty members to attain the title of professor. Other potential factors, such as the gender make-up of students graduating in different subject areas (eg, liberal arts vs Science, Technology, Engineering, \& Math [STEM] subjects), may also affect the speed of progress towards gender diversity for professors. Future studies should consider how gender differences in subject areas may influence progress towards gender diversity. Nevertheless, while non-Athena institutions had greater percentages of female non-managerial professors, HEIs with all levels of Athena SWAN accreditation/awards showed greater growth rates of female representation over time, suggesting the positive effects of applying and receiving the Athena awards on gender diversity among professors over time.

Having an Athena SWAN award, especially Silver award, is associated with a higher global ranking of the UK HEIs measured by the QS ranking overall scores. As suggested in prior research, ${ }^{22}$ this can be partly explained by institutions most affected by the NIHR funding being more motivated to pursue Silver awards. Higher ranking institutions may also have better financial resources to commit to the Athena SWAN initiative. Such factors have contributed to debate about whether awards are recognising what they ought to achieve. ${ }^{1}$ Future studies examining the effect of Athena SWAN awards could benefit from examining more dimensions of university performance and exploring how financial incentives and resources may affect motivations and abilities of HEIs to achieve gender equity.

\section{Strengths and limitations}

This study is the first quantitative study to examine gender diversity in managerial leadership and senior academic professor positions across UK HEIs with different Athena SWAN status in a longitudinal design. It adds to the existing research literature, which almost exclusively has a qualitative focus, ${ }^{328}$ through quantitatively assessing the relationship between these variables of interest.

We are mindful of the following limitations of this study. First, our study is advantageous to obtain relatively large sample across 5 years; however, it is possible that the effect of Athena SWAN may become more pronounced over longer periods. As suggested by latest evaluation studies, Athena SWAN is a complex intervention and could influence changes in female representation in different ways and mechanisms. ${ }^{2329}$ Thus, it is possible that substantial increases in female representation, especially at senior academic levels, will require more time. ${ }^{29}$ Future studies will do well to continue collecting data with longer periods with more data points and award details to examine the effect of Athena SWAN on gender diversity.

Second, besides quantitative analysis, qualitative studies examining how and why Athena SWAN might influence gender equality progress should be conducted to gain more understanding in its effect and offer useful suggestions for future practices.

Third, gender diversity in HEIs is affected by various social contextual factors (eg, culture, gross domestic product, policy, geography)..$^{2-611285}$ As the first quantitative study to explore the effect of Athena SWAN accreditation/awards, we did not control for these variables in the 
current analysis. Future research should consider these factors in analysing the effect of Athena SWAN.

Fourth, prior to 2015, Athena SWAN focused primarily on academic and research staff, ${ }^{25}$ while the HESA data used in this study cover 5 years from 2012/2013 to 2016/2017, and the contract levels A-E2 (defined as Leaders) include non-academic staff (eg, vice-chancellor/ principal/equivalent; director of major function/group of functions). Hence, the changes in the levels of gender diversity in the leadership position may be only indirectly attributable to Athena SWAN.

Fifth, the professor category in this study refers to senior academic rank (eg, professors without line management responsibilities) and might have lower mobility than lower rank faculty categories (eg, assistant professors). It is possible that the impact of Athena SWAN is greater among lower academic ranks, which were outside the scope of the current study. Future studies can include data of female representation among lower rank faculty positions and conduct a more comprehensive analysis of academics at different ranks.

Sixth, QS world ranking overall score was selected as a proxy indicator for university performance in this study and has some limitations related to using subjective ratings on institutional reputation, weightings and possibly biased survey to build a composite indicator. ${ }^{42}$ Future studies shall replicate the study using a suite of indicators with more stability and robustness.

Lastly, this study is based on HEIs with available employment data from HESA in the UK; the generalisability of its findings to UK HEIs and to other countries is yet to be determined. Future studies can also explore how other gender equity programmes, such as Organizational Change for Gender Equity in STEM Academic Professions in the USA, may affect gender diversity.

\section{CONCLUSION}

Under-representation of women in senior positions in HEIs has been widely identified as a major challenge to tackle, both in the UK and internationally. This study has revealed how Athena SWAN levels are related to gender diversity in HEIs. Despite overall positive trends towards gender diversity and positive associations between Athena SWAN level and increasing gender diversity for managerial leadership over time, the findings for full-time senior academics (ie, professors without managerial duties) indicate that Athena SWAN may need to look closely at whether receiving the award actually brings a meaningful and sustained commitment to gender diversity as intended. The relationship between research funding and criteria for achieving Athena SWAN levels of accreditation/awards warrants further attention to ensure appropriate institutional recognition and incentives. Finally, to address gender diversity in a broader cultural context and the degree to which the climate of the higher education environment is supportive of diversity, Athena SWAN could consider incorporating social marketing initiatives targeting attitudinal change, as shown in other domains, for instance, with the Time to Change campaign. ${ }^{43}$

Contributors Conception and design of the study: YX, EP, TKFA, PSFY. Data collection: EP, YX. Data analysis: YX. Interpretation of data: YX, EP, PSFY, TKFA. Drafting the manuscript: YX, EP. Revising the manuscript critically for important intellectual content: YX, EP, TKFA, PSFY. Approval of the version of the manuscript to be published: YX, EP, TKFA, PSFY.

Funding This research received funding for TKFA's Karen Lo Eugene Chuang Professorship in Diversity and Equity at the University of Hong Kong.

Competing interests None declared.

Patient consent for publication Not required.

Provenance and peer review Not commissioned; externally peer reviewed.

Data availability statement Data are available upon reasonable request and when the dissemination of the project's full results is completed.

Open access This is an open access article distributed in accordance with the Creative Commons Attribution Non Commercial (CC BY-NC 4.0) license, which permits others to distribute, remix, adapt, build upon this work non-commercially, and license their derivative works on different terms, provided the original work is properly cited, appropriate credit is given, any changes made indicated, and the use is non-commercial. See: http://creativecommons.org/licenses/by-nc/4.0/.

ORCID iD

Yunyu Xiao http://orcid.org/0000-0002-0479-1781

\section{REFERENCES}

1 Ovseiko PV, Chapple A, Edmunds LD, et al. Advancing gender equality through the Athena SWAN Charter for Women in Science: an exploratory study of women's and men's perceptions. Health Res Policy Syst 2017;15.

2 Rosser SV, Barnard S, Carnes M, et al. Athena SWAN and advance: effectiveness and lessons learned. The Lancet 2019;393:604-8.

3 Caffrey L, Wyatt D, Fudge N, et al. Gender equity programmes in academic medicine: a realist evaluation approach to Athena SWAN processes. BMJ Open 2016;6:e012090.

4 Bryant LD, Burkinshaw P, House AO, et al. Good practice or positive action? using $Q$ methodology to identify competing views on improving gender equality in academic medicine. BMJ Open 2017;7:e015973.

5 Jarboe N. Women count: leaders in higher education, 2018. Women count. Available: https://womencountblog.files.wordpress.com/2018/ 11/womencount-report-2018_web-version_new-final.pdf [Accessed 25 Nov 2019].

6 Laver KE, Prichard IJ, Cations M, et al. A systematic review of interventions to support the careers of women in academic medicine and other disciplines. BMJ Open 2018;8:e020380.

7 Ovseiko PV. Athena SWAN is taking flight 2019. Available: https:// www.timeshighereducation.com/opinion/athena-swan-taking-flight [Accessed 25 Nov 2019].

8 Latimer J, Cerise S, Ovseiko PV, et al. Australia's strategy to achieve gender equality in STEM. The Lancet 2019;393:524-6.

9 Medical Schools Council. A survey of staffing levels of medical clinical academics in UK medical schools at 31st July 2014. London: Medical Schools Council, 2015.

10 Medical Schools Council. Survey of medical clinical academic staffing levels 2018. London: Medical Schools Council, 2018.

11 Shollen SL, Bland CJ, Finstad DA, et al. Organizational climate and family life: how these factors affect the status of women faculty at one medical school. Acad Med 2009;84:87-94.

12 Messing K, Elabidi D. Desegregation and occupational health: how male and female Hospital attendants collaborate on work tasks requiring physical effort. Policy and Practice in Health and Safety 2003:1:83-103.

13 Marmot M, Friel S, Bell R, et al. Closing the gap in a generation: health equity through action on the social determinants of health. The Lancet 2008;372:1661-9.

14 Ovseiko PV, Greenhalgh T, Adam P, et al. A global call for action to include gender in research impact assessment. Health Res Policy Syst 2016;14:50.

15 Johnson P, Fitzgerald T, Salganicoff A, et al. Sex-specific medical research: why women's health can't wait. A report of the Mary Horrigan Connors Center for Women's Health \& Gender Biology at 
Brigham and Women's Hospital Brigham and Women's Hospital, 2014.

16 Allen I. Women doctors and their careers: what now? BMJ 2005;331:569-72.

17 Penny M, Jeffries R, Grant J, et al. Women and academic medicine: a review of the evidence on female representation. $J R$ Soc Med 2014;107:259-63.

18 Ovseiko PV, Edmunds LD, Pololi LH, et al. Markers of achievement for assessing and monitoring gender equity in translational research organisations: a rationale and study protocol. BMJ Open 2016;6:e009022.

19 Kelly U, McNicoll I. Through a glass, darkly: Measuringthe social value of universities. Bristol: National Co-ordinating Centre for Public Engagement, 2011.

20 Nyssen JM. The Social Dimension and University Rankings. In: European higher education area: the impact of past and future policies. Springer International Publishing, 2018: 155-69.

21 Equality Challenge Unit. Equality in higher education: statistical report 2015, 2016. Available: https://www.ecu.ac.uk/publications/ equality-higher-education-statistical-report-2015/

22 Gregory-Smith I. The impact of Athena SWAN in UK medical schools. In: The Sheffield economic research paper series (SERPS), 2015.

23 Schmidt EK, Ovseiko PV, Henderson LR, et al. Understanding the Athena SWAN Award scheme for gender equality as a complex social intervention in a complex system: analysis of Silver Award action plans in a comparative European perspective. bioRxiv 2019.

24 Munir F, Mason C, McDermott H. Evaluating the effectiveness and impact of the Athena SWAN charter. London: Equality Challenge Unit, 2014.

25 Ovseiko PV, Pololi LH, Edmunds LD, et al. Creating a more supportive and inclusive university culture: a mixed-methods interdisciplinary comparative analysis of medical and social sciences at the University of Oxford. Interdiscip/ Sci Rev 2019;44:166-91.

26 Tzanakou C. Unintended consequences of gender-equality plans: nature, 2019. Available: https://www.nature.com/articles/d41586019-01904-1 [Accessed 27 Nov 2019].

27 Gregory-Smith I. Positive action towards gender equality: evidence from the Athena SWAN charter in UK medical schools. Br J Ind Relat 2018;56:463-83.

28 Ovseiko PV, Chapple A, Edmunds LD, et al. Advancing gender equality through the Athena SWAN charter for women in science: an exploratory study of women's and men's perceptions. Health Res Policy Syst 2017;15:12.

29 Graves A, Rowell A, Hunsicker E. An impact evaluation of the Athena SWAN charter (2019). Advance HE, 2019.
30 Higher Education Statistics Agency (HESA). Staff record 2016/17 combined levels 2016. Available: http://www.hesa.ac.uk/collection/ c16025/combined_levels [Accessed 10 Apr 2019].

31 Equality Challenge Unit. Athena SWAN resources: Equality Challenge Unit, 2019. Available: https://www.ecu.ac.uk/equalitycharters/athena-swan/athena-swan-resources/ [Accessed 27 Nov 2019].

32 Equality Challenge Unit. Athena SWAN award criteria - institutions: Equality Challenge Unit, 2019.

33 Shanghai Ranking Consultancy. Shanghai ranking's academic ranking of World universities 2019. Available: http://www. shanghairanking.com/

34 Centre for Science and Technology Studies. CWTS Leiden ranking 2019, 2019. Available: https://www.leidenranking.com/ [Accessed 27 Nov 2019].

35 Times Higher Education. Times higher education world university rankings 2019. Available: https://www.timeshighereducation.com/ content/world-university-rankings [Accessed 27 Nov 2019].

36 QS Quacquarelli Symonds Limited. QS world university rankings: QS Quacquarelli Symonds limited, 2019. Available: https://www. topuniversities.com/qs-world-university-rankings/methodology [Accessed 24 Nov 2019].

37 Huang $\mathrm{M}-\mathrm{H}$. Opening the black box of QS world university rankings. Res Eval 2012;21:71-8.

38 Singer JD, Willett JB. Applied longitudinal data analysis: modeling change and event occurrence. New York, NY: Oxford University Press, 2003.

39 Equality Challenge Unit. Athena SWAN members: Equality Challenge Unit, 2019. Available: https://www.ecu.ac.uk/equality-charters/ athena-swan/athena-swan-members/ [Accessed 27 Nov 2019].

40 Joecks J, Pull K, Vetter K. Gender diversity in the boardroom and firm performance: What exactly constitutes a "critical mass?". J Bus Ethics 2013;118:61-72.

41 Higher Education Statistics Agency (HESA). What do HE students study 2018. Available: https://www.hesa.ac.uk/data-and-analysis/ students/what-study [Accessed 10 Apr 2019].

42 Dobrota M, Bulajic M, Bornmann L, et al. A new approach to the QS university ranking using the composite I-distance indicator: uncertainty and sensitivity analyses. J Assoc Inf Sci Technol 2016;67:200-11.

43 Evans-Lacko S, Corker E, Williams P, et al. Effect of the time to change anti-stigma campaign on trends in mental-illness-related public stigma among the English population in 2003-13: an analysis of survey data. Lancet Psychiatry 2014;1:121-8. 